ACCEPTED MANUSCRIPT

\title{
Carbon-based nanomaterial synthesis using nanosecond electrical discharges in immiscible layered liquids: $n$-heptane and water
}

To cite this article before publication: Ahmad Hamdan et al 2018 J. Phys. D: Appl. Phys. in press https://doi.org/10.1088/1361-6463/aac46f

\section{Manuscript version: Accepted Manuscript}

Accepted Manuscript is "the version of the article accepted for publication including all changes made as a result of the peer review process, and which may also include the addition to the article by IOP Publishing of a header, an article ID, a cover sheet and/or an 'Accepted Manuscript' watermark, but excluding any other editing, typesetting or other changes made by IOP Publishing and/or its licensors"

This Accepted Manuscript is @ 2018 IOP Publishing Ltd.

During the embargo period (the 12 month period from the publication of the Version of Record of this article), the Accepted Manuscript is fully protected by copyright and cannot be reused or reposted elsewhere.

As the Version of Record of this article is going to be / has been published on a subscription basis, this Accepted Manuscript is available for reuse under a CC BY-NC-ND 3.0 licence after the 12 month embargo period.

After the embargo period, everyone is permitted to use copy and redistribute this article for non-commercial purposes only, provided that they adhere to all the terms of the licence https://creativecommons.org/licences/by-nc-nd/3.0

Although reasonable endeavours have been taken to obtain all necessary permissions from third parties to include their copyrighted content within this article, their full citation and copyright line may not be present in this Accepted Manuscript version. Before using any content from this article, please refer to the Version of Record on IOPscience once published for full citation and copyright details, as permissions will likely be required. All third party content is fully copyright protected, unless specifically stated otherwise in the figure caption in the Version of Record.

View the article online for updates and enhancements. 


\title{
Carbon-based nanomaterial synthesis using nanosecond electrical discharges in immiscible layered liquids: $\boldsymbol{n}$-heptane and water
}

\author{
Ahmad Hamdan ${ }^{1}$ and Min Suk Cha ${ }^{2}$ \\ ${ }^{1}$ Groupe de physique des plasmas, Département de Physique, Université de Montréal, C.P. \\ 6128, Succ. Centre-Ville, Montréal, Québec, H3C 3J7, Canada \\ ${ }^{2}$ King Abdullah University of Science and Technology (KAUST), Clean Combustion \\ Research Center (CCRC)/ Physical Science and Engineering Division (PSE), Thuwal 23955, \\ Saudi Arabia \\ Corresponding authors: ahmad.hamdan@umontreal.ca; min.cha@kaust.edu.sa
}

\section{Keywords}

Carbon nanomaterial, nanosecond discharge, plasma in liquids, characterization of nanomaterial. 
Plasmas in- or in-contact with liquids have been extensively investigated due to their high potential for a wide range of applications including but not limited to, water treatment, material synthesis and functionalization, bio-medical applications, and liquid fuel reformation. Recently, we successfully developed a discharge using two immiscible liquids, having very different electrical permittivities, which could significantly intensify the electric field intensity. Here, we establish nanosecond discharges at the interface $n$-heptane-water (with respective relative dielectric permittivities of 2 and 80 ) to enable the synthesis of carbon-based nanomaterials. A characterization of the as-synthesized material and the annealed $\left(500{ }^{\circ} \mathrm{C}\right)$ material, using various techniques (Fourier-Transform, Infra-Red, Scanning and Transmission electron microscopes, etc.), shows that the as-synthesized materialis a mixture of two carbonbased phases: a crystalline phase (graphite like) embedded into a phase of hydrogenated amorphous carbon. The existence of two-phases may be explained by the non-homogeneity of the discharge that induces various chemical reactions in the plasma channel. 


\section{INTRODUCTION}

The chemical element 'carbon' has an extraordinary ability to combine with either itself or with other chemical elements. A wide range of carbon materials, both crystalline and amorphous, are built solely with carbon atoms assembled in structures of macro-, micro-, or nano-scale dimensions [1-4]. Nano-carbon-based structures such as single- or multi-wall carbon nanotubes [5], carbon nano-cones [6], fullerenes [7], graphene [8], or nano-onions [9], have generated an extraordinary amount of interest. Indeed, at the nano-scale, materials exhibit extraordinary electrical, optical, mechanical, and chemical properties [10, 11].

The carbon-carbon bond can be single (e.g., alkanes: $\left.\mathrm{C}_{\mathrm{n}} \mathrm{H}_{2 \mathrm{n}+2}\right)$, double (e.g., alkenes: $\mathrm{C}_{\mathrm{n}} \mathrm{H}_{2 \mathrm{n}}$ ) or triple (e.g., alkynes: $\mathrm{C}_{\mathrm{n}} \mathrm{H}_{2 \mathrm{n}-2}$ ). Carbon allotropic forms and phases are often classified by hybridization type. For example, diamond possesses a $\mathrm{sp}^{3}$ hybridization, whereas graphite has a $\mathrm{sp}^{2}$ hybridization. In addition, there are many transitional forms in which $\mathrm{sp}^{2}$ and $\mathrm{sp}^{3}$ hybridization bonds coexist in the same solid. This is the case for amorphous carbon, carbon black, soot, cokes, glassy carbon, etc. $[12,13]$. Other forms of hybridization have also been observed, such as altering single and triple bonds (polyyne) or altering single and double bonds (polycumulene) with stabilizing molecular/complexes at the end of the chains $[14,15]$.

There are numerous methods and techniques to synthesize carbon-based materials. For gas phase synthesis, chemical vapor deposition (CVD) [16] and plasma-enhanced CVD (PECVD) [17] are well-known and widely used techniques in industrial applications. Both CVD and PE-CVD are based on the use of chemicals coupled with high temperature and/or plasmas, and may present toxicity risks. For example, the synthesis of CNT by CVD produces many toxic and greenhouse by-products (45 side-products identified to this day [18]) that have damaging impacts for the environment. Additionally, nanoparticles, which have the ability to 
penetrate the body through the skin and lungs can deposit in various organs, carrying the risk of undesirable reactions by modifying the physiochemical properties of the living matter [19].

There are efficient and safer ways to synthesize carbon-based materials using in-liquid plasma processes [20-23]. For example, in-liquid, non-thermal plasmas can be created by, for instance nanosecond electrical discharge [24-26]. For the synthesis of carbon-based materials using in-liquid non-thermal plasmas, liquid hydrocarbons are mostly considered as a feedstock. Particular reasons to employ nanosecond discharges for in-liquid plasmas are to guarantee that the discharge occurs in the liquid phase (joule heating and evaporation can be neglected) and to ensure the non-thermal properties of the plasma $[27,28]$. Therefore, various radicals and reactive species are created efficiently, and nanomaterials can thus be obtained by mutual interaction of these species and agglomeration.

In-liquid discharges offer numerous benefits, such as high yields of produced nanomaterials $[28,29]$, minimal airborne side-effects on human health and environment, due to their confinement within liquids. Very often, in-liquid discharges for the synthesis of nanomaterials are designed to be used in arc and spark modes between electrodes immersed in liquids [30, 31], or to apply a microwave power to a metallic electrode immersed in a liquid phase [32]. In all cases, in particular when hydrocarbon liquids with low dielectric permittivity $(\varepsilon)$, the plasma-electrode interaction is expected to be strong, leading to electrode erosion that will eventually result in the contamination of nanomaterials. For example, it was shown that discharges between two metal electrodes in hydrocarbon liquids lead to a composite material, i.e., metallic nanoparticles (from the electrode) embedded in carbonaceous matrix (from the liquid) $[27,33]$.

Streamer-mode discharges have been rarely investigated for their potential use in creating nanomaterials as liquids (e.g., hydrocarbons and organosilicons) have a very low $\varepsilon$, and thus a high breakdown voltage. The challenge is then to develop techniques and methods 
that decrease the cost of discharges in low- $\varepsilon$ liquids. For this, we recently introduced a new method presenting significant benefits and could be instrumental in the synthesis of nanomaterials [29]. This method is based on the discharge in layered two immiscible liquids [34]. The basic physics of the method, as well as its experimental implementation are detailed in Section 2.

\section{EXPERIMENTAL SETUP AND CHARACTERIZATION TOOLS}

\subsection{Nanosecond discharges at the interface of $\boldsymbol{n}$-heptane-water}

Polar and non-polar liquids do not mix together and usually form a layered structure due to their different densities, similarly to what is observed in a water-oil system. At the interface, there is a discontinuity in liquids' permittivity and density.

a)

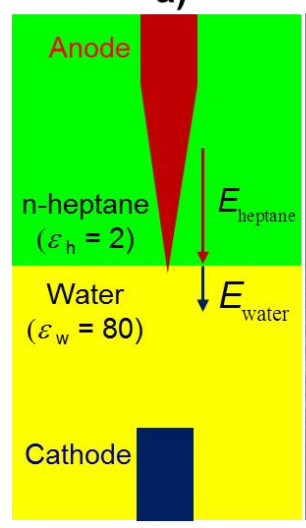

b)

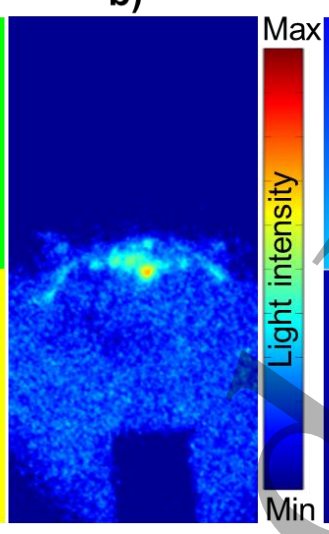

c)

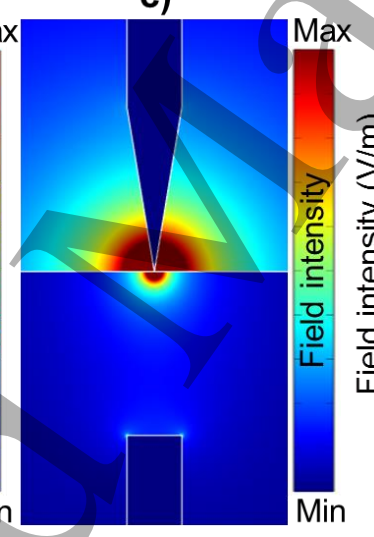

d)

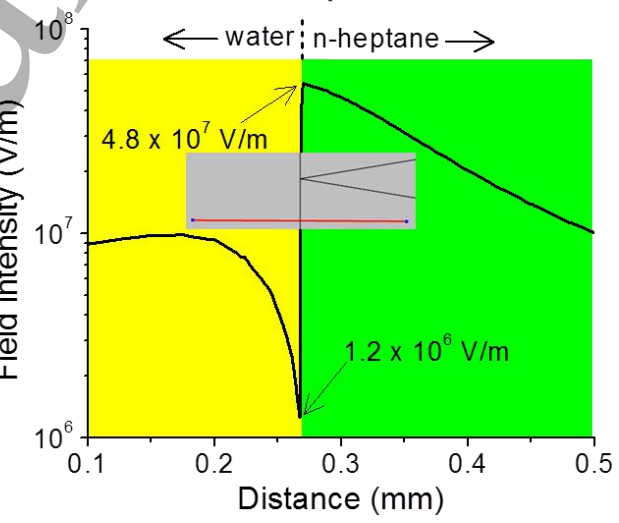

Figure 1. a) Schematic of the experimental setup (not drawn to scale) showing the anode, the cathode, $n$-heptane, water, and the interface. $b$ ) ICCD image (integrated over $1 \mu \mathrm{s}$ ) of the discharge at the interface $n$-heptane-water (15 kV of applied voltage and $2 \mathrm{~mm}$ of gap distance). c) $2 \mathrm{D}$ electric field simulation using Comsol Multiphysics for conditions similar to b). d) Electric field profile along a line (the red line in the inset) crossing the interface close to the anode.

The effects of the permittivity's discontinuity on nanosecond discharges, in liquid media, were previously discussed [29, 34]. We observed that the gradient of electric field intensity at a liquid-liquid interface significantly facilitates the discharge, in terms of applied voltage and active plasma volume, depending on the location of the high-voltage anode. 
Specifically, we find that, when the anode tip is positioned at the interface n-heptane-water with the ground electrode in the water (figure 1a), we can obtain the lowest applied voltage to achieve consistent discharges, per each pulse, without misfire. As a result, the plasma channels that are created propagate along the interface, dissociating both liquids (figure 1b). The physical mechanisms of the augmented discharge probability and volume in the layered liquids may be the result of a fundamental law of electrostatics, i.e., the normal component of the electric displacement field, $D_{\mathrm{n}}=\varepsilon E_{\mathrm{n}}$, is continuous along the interface. Therefore, the normal component of $E$ is intensified by the ratio of the permittivities of both liquids.

In this study, we chose to investigate nanosecond discharges at the interface of two liquids in order to determine the feasibility of our method with respect to carbon nanomaterial synthesis. We used $n$-heptane as a source of carbon, and water as a supporting high- $\varepsilon$ substance of the discharge. Our experimental setup involved filling up a $5 \times 5 \times 10-\mathrm{cm}^{3}$ quartz test cell with $100 \mathrm{~mL}$ of distilled water and $100 \mathrm{~mL}$ of $n$-heptane. These two liquids form the liquid-liquid interface, with the $n$-heptane layer (density of $0.68 \mathrm{~g} / \mathrm{cm}^{3}$ ) above the water layer (density of 1 $\mathrm{g} / \mathrm{cm}^{3}$ ). Two tungsten rods (1-mm diameter) are submerged vertically in order for the tip of the high-voltage anode (upper) to be at the interface of the two liquids, and the ground electrode (lower) to be located in water. The radius of curvature of the anode tip is $\sim 50 \mu \mathrm{m}$, whereas the end of the ground electrode is flat. The inter-electrode distance is $2 \mathrm{~mm}$.

We use a nanosecond high voltage pulser (FID, FPG-25-15NM) in a single pulse mode with an applied voltage of $15 \mathrm{kV}$; the full-width at half-maximum of the pulse is $\sim 10 \mathrm{~ns}$. Figure 1b shows the discharge emission morphology captured by an ICCD camera (PI-MAX3, Princeton Instruments), with an integration time of $1 \mu \mathrm{s}$. As the electrode tip is positioned at the interface of $n$-heptane-water, the discharge develops and propagates mostly horizontally along the interface, showing a pancake-like structure. To understand the physics behind this novel mode of discharge we conduct a simplified 2D simulation of the electrical field 
distribution, under similar conditions to those reported in figure 1b. Our simulation (figure 1c) shows an augmentation of the electric field intensity at the interface, particularly on the $n$ heptane side (in comparison with the water side) leading to an important gradient across the interface. Figure 1d shows a plot of the normal component of the electric field along a line crossing the interface (red line in the inset). The field intensity measured at the interface, from the $n$-heptane and water sides are $4.8 \times 10^{7} \mathrm{~V} / \mathrm{m}$ and $4.2 \times 10^{6} \mathrm{~V} / \mathrm{m}$, respectively. The ratio of these two intensities is 40 , i.e., exactly the ratio $\varepsilon_{\text {water }} / \varepsilon_{n \text {-heptane }}(80 / 2)$. This result explains why discharges are facilitated in the presence of layered liquids with significantly different permittivities.

\subsection{Discharge conditions for nanomaterial synthesis and characterization tools}

Using an experimental setup similar to that described in Section 2.1, the high-voltage is increased from +15 to $+25 \mathrm{kV}$, and the repetition rate is set at $6.4 \mathrm{kHz}$. The duration of the discharge operation to produce synthesized materials is five minutes.

A FTIR (Fourier Transform Infra-Red) spectrometer (Nicolet, 6700) was used to analyze the composition of both liquid and solid samples (after liquid evaporation), based on the values of the absorption spectra within a $500-4000 \mathrm{~cm}^{-1}$ range, and for a spectral resolution of $4 \mathrm{~cm}^{-1}$. The analysis was conducted in ATR (Attenuated Total Reflection) mode. The liquid samples were analysed by adding liquid droplets on the window, while the solid samples were analysed after evaporating the liquid droplet previously deposited onto the window. Values obtained are corrected using a background spectrum acquired with no sample under the same conditions. For the deconvolution of signal peaks, a straight line is removed to obtain a constant base line, which facilitates the fitting process; Gaussian functions are used.

A Magellan XHR 400 FEG is used for high-resolution scanning electron microscopy (SEM) analysis. Samples are analyzed with a transmission electron microscopy (TEM) to 
determine their morphologies, crystalline structures, and elemental compositions. The TEM analysis is conducted using a Titan 60-300 ST electron microscope from FEI Company (Hillsboro, OR). This microscope is equipped with an image corrector to decrease the coefficient of the spherical aberration of the objective lens, so that an image-corrected TEM analysis can be performed. The morphology of the samples is examined by acquiring lowmagnification images in the bright-field TEM mode. Selected area electron diffraction (SAED) patterns from the samples are also acquired to investigate the crystal structure of the samples. We use a high-resolution TEM at high magnification to observe details at the nanoscale level. Finally, Raman characterizations are carried out using Horiba LabRaman Aramis equipped with laser at $325 \mathrm{~nm}$, and the spectra are acquired from 200 to $3000 \mathrm{~cm}^{-1}$.

The chemical and microstructural stabilities of the synthesized nanomaterial are assessed by thermal annealing, conducted using an oven with air as ambient gas. The annealing of one set of samples is performed at $500{ }^{\circ} \mathrm{C}$, for two hours. Samples are mounted in the oven at the beginning of the procedure (room temperature), and until the final temperature $\left(500{ }^{\circ} \mathrm{C}\right)$ is reached, and before undergoing the annealing process, for two hours, at $500{ }^{\circ} \mathrm{C}$. Note that a linearly increased temperature profile was used to a target temperature.

\section{RESULTS AND DISCUSSION}

Nanosecond discharges at the interface of n-heptane-water resulted in the decomposition of $\mathrm{n}$-heptane (and water) and the production of carbon-based materials. Based on current-voltage characteristics, we assume that the consumed energy during 5 minutes of processing is $\sim 250 \mathrm{~J}$. The production rate of material is $\sim 20 \mathrm{mg}$ after 5 minutes of processing. Leading thus to an efficiency of $\sim 12.5 \mathrm{~J} / \mathrm{mg}$. Note that the plasma processing induced a change in color only in the n-heptane side, indicating, therefore, that the synthesized materials are dissolved only in n-heptane; the FTIR analysis on water after processing does not show any 
changes. The synthesized materials were identified and characterized, using various techniques presented below. FTIR was used to analyze the plasma-processed $n$-heptane (liquid sample), collected after five minutes of continuous discharges. Figure 2 presents a comparison of the FTIR spectra for the plasma-processed $n$-heptane and for the synthesized solid materials obtained after evaporating the liquid with that of untreated $n$-heptane. Comparing two spectra for the plasma-treated and untreated liquids, no significant difference could be found being attributed by large contribution of $n$-heptane to the result. Therefore, to collect solid particles, we left the liquid sample at room temperature for 24 hours to evaporate $n$-heptane and other byproducts. For the solid samples, we observed a significant difference in the FTIR spectrum (figure 2), particularly for the wavenumbers between 600 and $1800 \mathrm{~cm}^{-1}$ that correspond to different vibration modes of the $\mathrm{CH}, \mathrm{CH}_{2}$, and $\mathrm{CC}$ bonds [35]. Additionally, we noticed a change of the relative shape of the peaks between 2700 and $3150 \mathrm{~cm}^{-1}$, compared to those for the plasma-treated liquid sample. New low-intensity peaks appeared at $\sim 3060 \mathrm{~cm}^{-1}$ and $\sim 3300$ $\mathrm{cm}^{-1}$, with the solid sample; those were attributed to $\mathrm{sp}^{2} \mathrm{CH}$ and $\mathrm{sp}^{1} \mathrm{CH}$, respectively [36]. The wide range of absorption band in $3200-3600 \mathrm{~cm}^{-1}$ is attributed to $\mathrm{OH}$. So far, this $\mathrm{OH}$ could be due to the presence of some residual water in the material originating from the process itself (discharge in $n$-heptane-water) or from after processing (humidity) as the measurement were conducted in air. Oxygen is not present in the structure as confirmed by other analysis techniques, e.g., energy-dispersive X-ray spectroscopy (not shown here) during TEM characterization. Note that we could not confirm the residue of heptane after the evaporation process captured within the carbon layers based on the current analysis. 


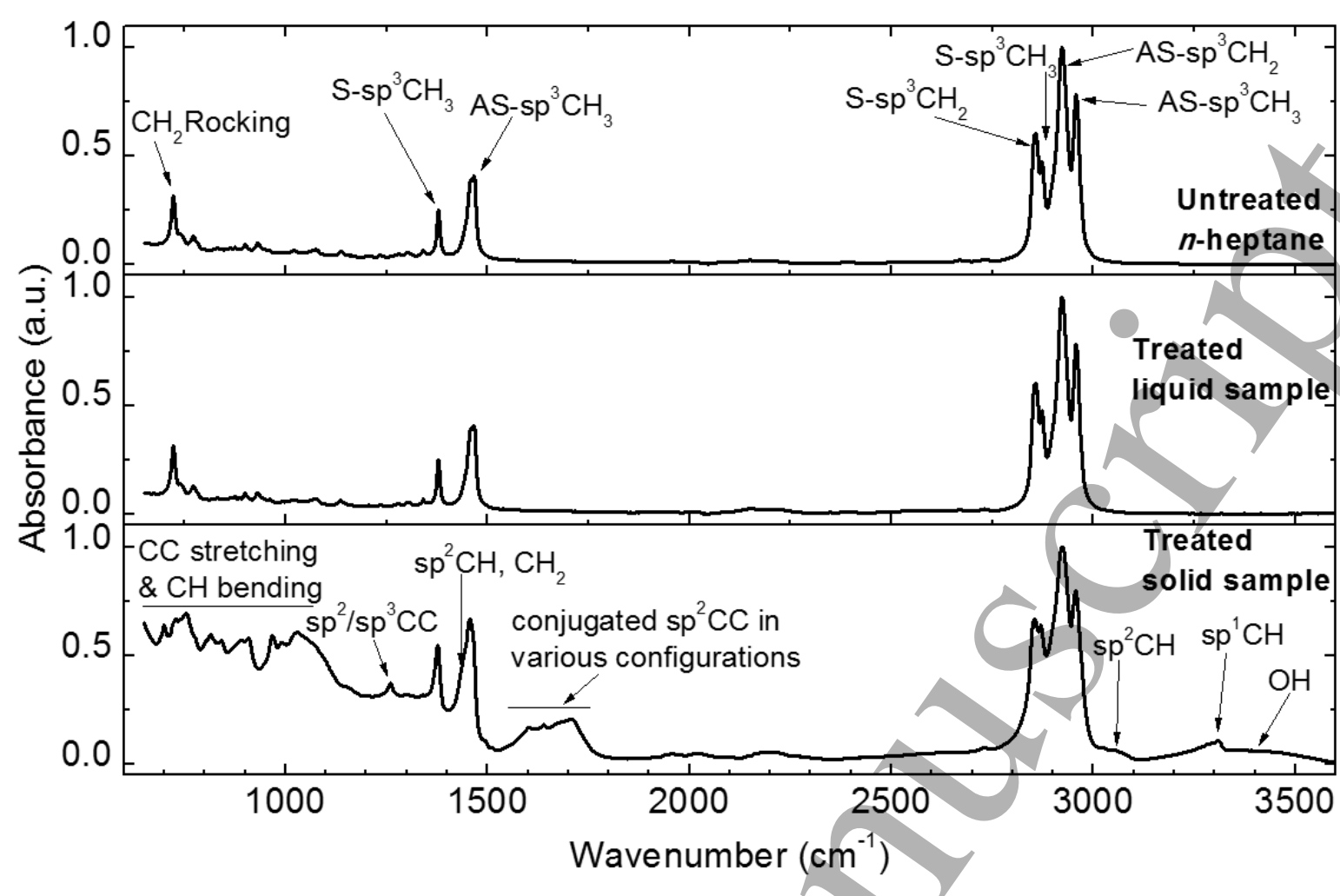

Figure 2. FTIR spectra (absorbance) of untreated liquid n-heptane, liquid-treated n-heptane, and synthesized solid particles.

Recognizing the absorbance signals within a range of $2700-3000 \mathrm{~cm}^{-1}$ were common for the all liquid and solid samples exhibiting strong signal intensities. To better understand the structure of the synthesized materials, we conducted an in-depth investigation of the collected data, using a profile fitting method with multiple Gaussian functions; results are presented in figure 3. Figure 3a shows the five elementary components of the overall shape, and each peak can be identified as a known vibrational mode. 2856 and $2874 \mathrm{~cm}^{-1}$ correspond to $\mathrm{sp}^{3} \mathrm{CH}_{2}$ and $\mathrm{sp}^{3} \mathrm{CH}_{3}$ symmetric vibrational modes, respectively, 2924 and $2958 \mathrm{~cm}^{-1}$ correspond to $\mathrm{sp}^{3} \mathrm{CH}_{2}$ and $\mathrm{sp}^{3} \mathrm{CH}_{3}$ asymmetric vibrational modes, respectively, and $2895 \mathrm{~cm}^{-1}$ corresponds to the $\mathrm{sp}^{3} \mathrm{CH}$ vibrational mode. These peaks are widely used as a representation of the vibrational modes of $n$-heptane molecule for a wavenumber range of $2700-3000 \mathrm{~cm}^{-1}$ [37]. As previously mentioned, it was not possible to detect by FTIR solid particles in the liquid phase. Because of this, the profile fitting of the solid material was conducted using the same elementary components centered at 2856, 2874, 2895, and $2958 \mathrm{~cm}^{-1}$ (figure $3 \mathrm{~b}$ ). We found that the peak 
at $2895 \mathrm{~cm}^{-1}$ became very large in terms of the peak and the width of the Gaussian profile, while the other elementary components showed significantly decreased peak intensities and widths. Note that the best fit for the solid material could not be obtained if the peak at 2924 $\mathrm{cm}^{-1}$ (liquid sample) was kept at the same position. In our study, two contributions were identified at 2914 and $2926 \mathrm{~cm}^{-1}$ : these two peaks correspond to the $2924 \mathrm{~cm}^{-1}$ vibrational mode (asymmetric $\mathrm{sp}^{3} \mathrm{CH}_{2}$ ), and the change in wavenumbers is due to the network where bands are located [38]. The multiplicity of absorbance signals at smaller wavenumbers $\left(<1800 \mathrm{~cm}^{-1}\right)$, in contrast with the significantly different observations made for higher wavenumbers $(>2700$ $\mathrm{cm}^{-1}$ ) clearly showed that the chemical structure of the solid synthesized materials contained $\mathrm{CH}, \mathrm{CH}_{2}, \mathrm{CH}_{3}, \mathrm{C}-\mathrm{C}$, and $\mathrm{C}=\mathrm{C}$ groups, and that, therefore, the material was likely a hydrogenated carbon.

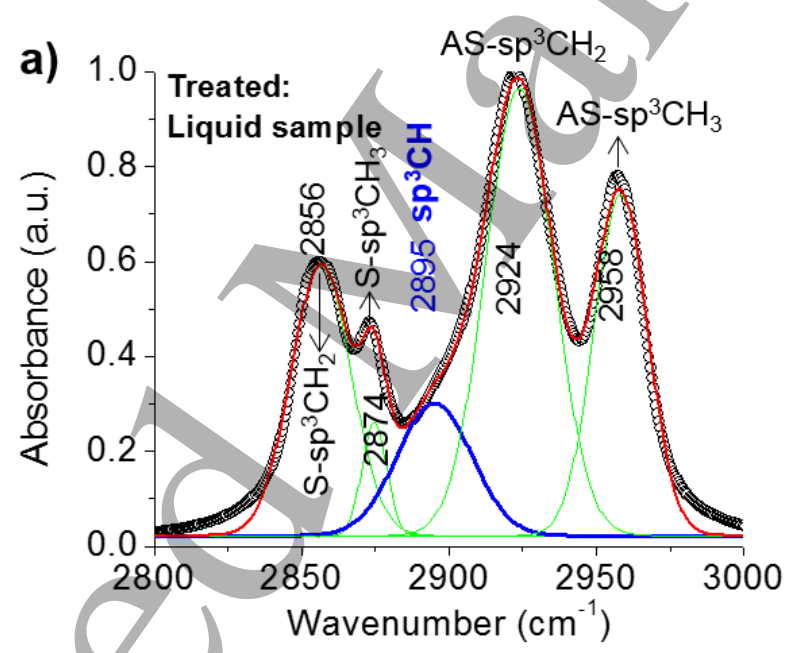

b) 1.0 Treated:

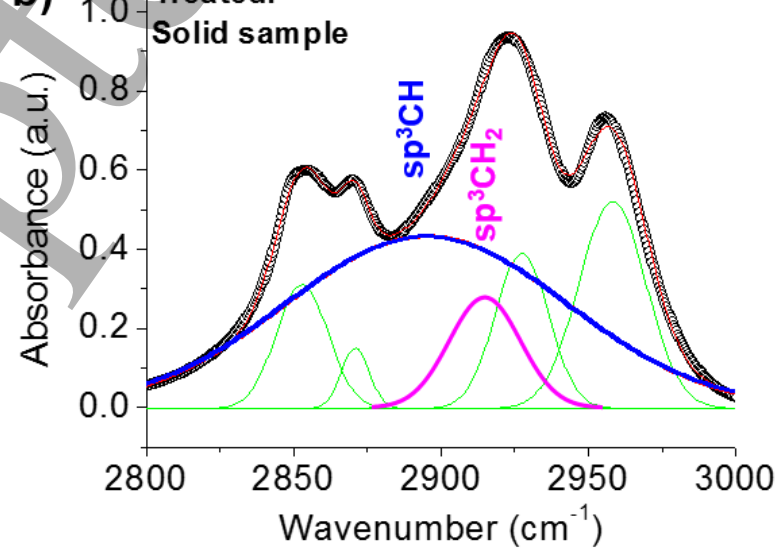

Figure 3. Fitting of the FTIR spectra (absorbance) of a) treated liquid n-heptane and $b$ ) synthesized solid particles. 
To obtain information about the morphology of the synthesized solid material, SEM imaging was performed after evaporating a treated liquid $n$-heptane droplet (at room temperature) on an $\mathrm{Al}$ substrate. The structure of the synthesized solid material was identified as a discontinuous, sheet-like, micro- and nano-structure (figure $4 \mathrm{a}$ ). Single sheets were also observed (figure $4 \mathrm{~b}$ ). Figure $4 \mathrm{~b}$ shows the presence of twisted nano-sheets on the surface of the single sheet. At higher resolution, it is possible to see that the surface of the sheet is 'decorated' by nanoparticles.

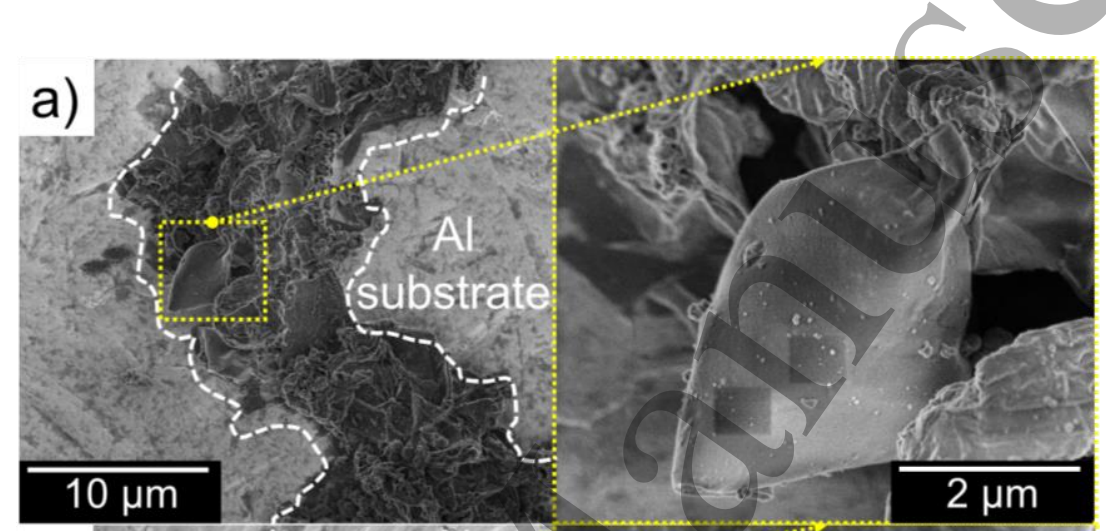

Figure 4. SEM images of the as-synthesized material deposited onto an aluminum substrate. a) Image showing multiple sheets; $b$ ) image showing one single sheet decorated by nanoparticles.

TEM images, shown in figure 5, confirmed our assumption that the material was made of an assembly of multiple sheets. As shown in figure 5a, the superimposition of multiple sheets locally increased the contrast and it appeared like they might be nanoparticles. However, observations made at higher resolution (figure $5 \mathrm{~b}$ and c) clearly showed that there were no nanoparticles embedded in the sheet, and that what looked like nanoparticles, in figure 5a, were 
the result of multiple layers of sheets. On the other hand, both ultra-high resolution images (figure 5c) and electron diffraction patterns (figure 5d) confirmed the amorphous structure of the material. The electron energy loss spectrum C K-edge represented in figure 5e clearly showed the carbon transition, $\pi^{*}$ and $\sigma^{*}$, a characteristic of the amorphous carbon [39]. Thus, the material consists of layers of amorphous carbon, stacked upon each other.
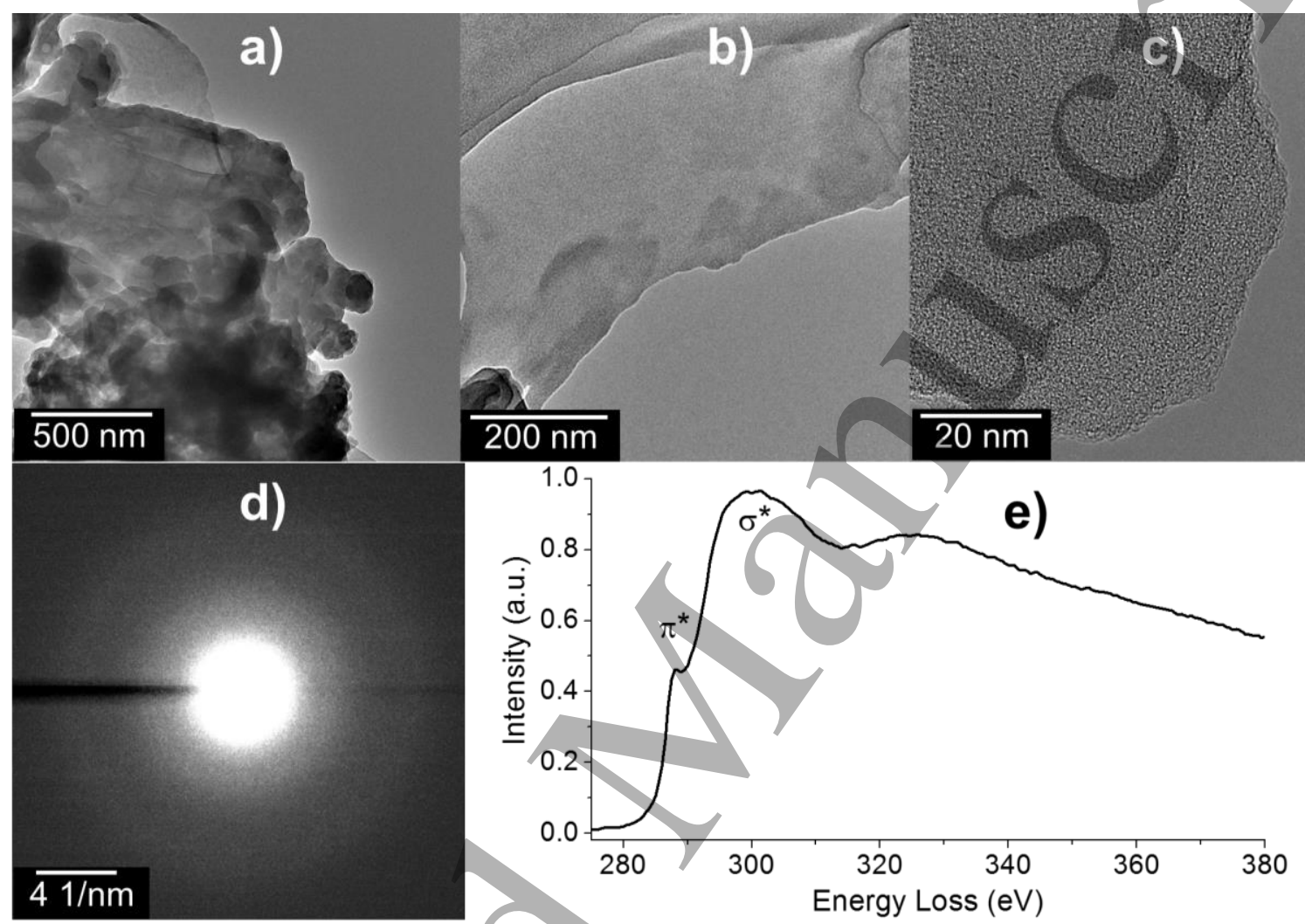

Figure 5. TEM images of the as-synthesized material at a) low, b) intermediate, and c) high resolution. d) Electron diffraction pattern of the as-synthesized material. e) Electron energy loss spectrum of the as-synthesized material.

Raman spectroscopy was performed to obtain information on the carbon structure in the material. The obtained spectrum (figure 6) showed the presence of a peak at $1389 \mathrm{~cm}^{-1}$ (known as ' $D$ ' peak for Disorder), and a peak at $1596 \mathrm{~cm}^{-1}$ (known as 'G' peak for Graphite). The position $\left(\sim 1596 \mathrm{~cm}^{-1}\right)$ and the width $\left(\sim 65 \mathrm{~cm}^{-1}\right)$ of the $\mathrm{G}$ peak, as well as the ratio of D/G peaks (area $\sim 2.66$, intensity $\sim 0.52$ ) indicate that the synthesized solid material belonged to the family of short-range order hydrogenated amorphous carbon [40, 41]. 


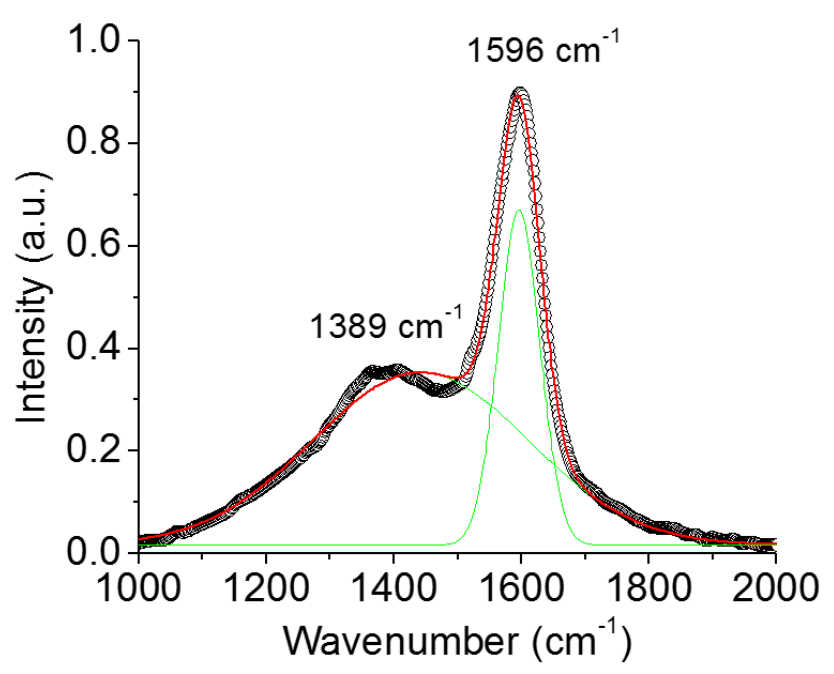

Figure 6. Raman spectrum of the as-synthesized material showing D and $G$ peaks at 1389 and $1596 \mathrm{~cm}^{-1}$.

To obtain a good chemical and physical stability of the material, the synthesized solid material was thermally annealed at $500{ }^{\circ} \mathrm{C}$, with air at atmospheric pressure, for two hours. In general, the annealing process causes the release of hydrogen from $\mathrm{CH}_{\mathrm{x}}$ groups [42] and creates nano-sized voids that can improve some properties of the material e.g., the relative dielectric constant $[42,43]$. Because there was no liquid in the annealed sample, we added a methanol solution for SEM and TEM measurements; droplets of the material dissolved in methanol solution were then evaporated, on an Al substrate for SEM, and on a grid for TEM observations.

Typical SEM images are presented in figure 7. In this figure, large objects surrounded by micro- and nano-objects can be identified (figure 7a). The high resolution of the large object shows that its surface present holes induced by thermal annealing (figure $7 \mathrm{~b}$ and $\mathrm{d}$ ). Because the melting temperature of carbon (in almost all allotropic forms) is relatively high ( 4000$5000 \mathrm{~K}$ ), the hole-structure was expected to be a result of releasing low-energy bond structures (e.g., hydrogenated carbon). Such a phenomenon is well utilized to produce subtractive porous (low-k) materials, and they are usually produced by thermal desorption of some sacrificial particles or porogens [44]. A priori, our synthesized material does not have such porogens in its structure, thus the holes should be attributed to the evaporation of the low-energy bond 
structures by heating. The objects at the substrate surface (figure $7 \mathrm{c}$ ) can thus be attributed to the residual material with a high and stable energy structure. These objects have a length of 5$15 \mu \mathrm{m}$ and a width of 1-3 $\mu \mathrm{m}$. Although we did not measure the thickness of these objects, we expected them to be of different values as they exhibited different contrasts in the images. The relatively thick objects (darker ones) seemed to be well-stuck at the surface, whereas the relatively thin objects (lighter ones) sometimes showed a rolled-up structure indicating a needle like-structure. Such rolled-up structures are well known in literature as nanoscrolls [45]. They are morphologically similar to multiwalled nanotubes, but they present open extremities and side, since the edges of the scrolled sheets are not fused. Carbon nanoscrolls have very interesting properties enabling them to be successfully integrated with many applications, such as in electronic devices (e.g., circuit interconnects) [46], in micro-electro-mechanical systems (e.g., electro-actuators) [47], gas storage [48], etc.
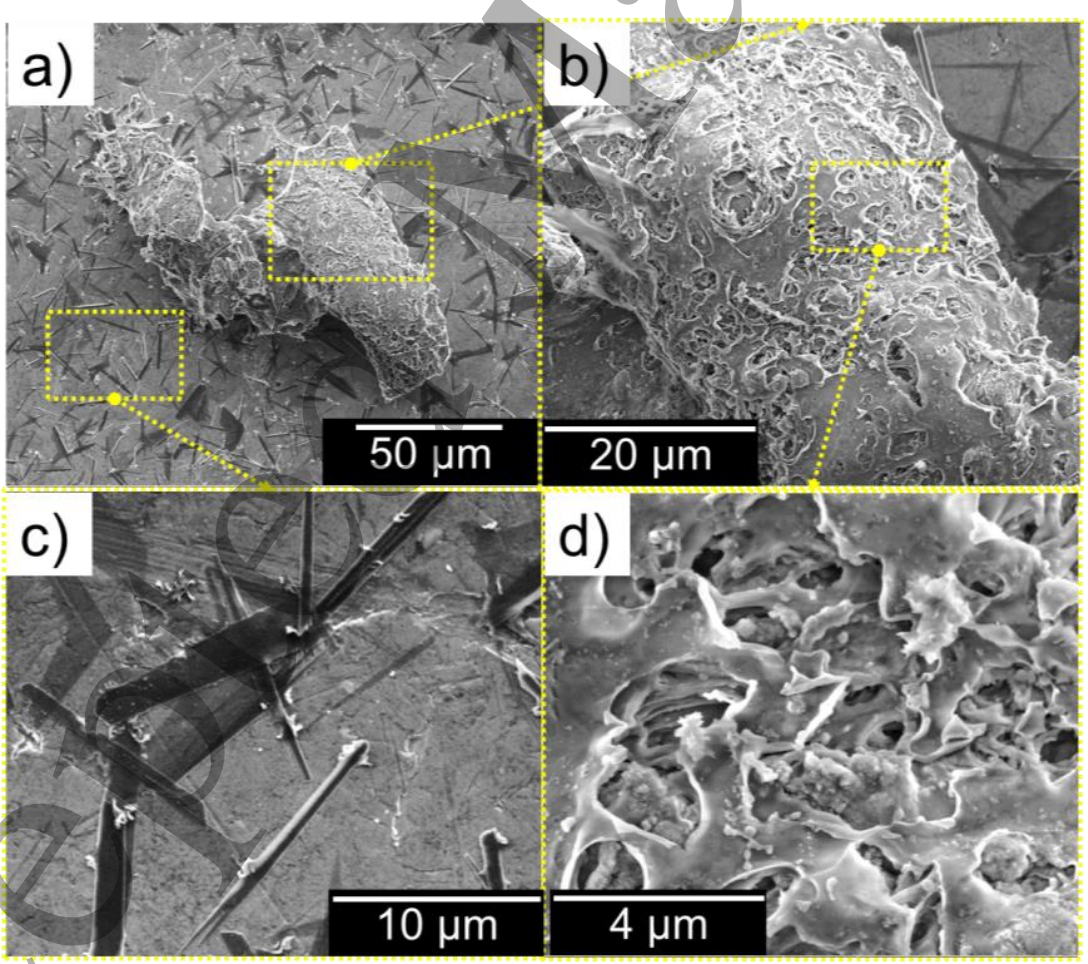

Figure 7. a) SEM images of the annealed material at $500{ }^{\circ} \mathrm{C}$ for two hours, with. b), c), and

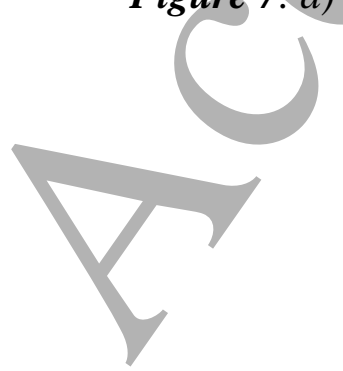

d) showing various regions of a) at higher magnification. 
Although very unstable under the electron beam, some TEM images and electron diffraction patterns were successfully acquired. TEM observations, shown in figures $8 \mathrm{a}$ and $\mathrm{b}$, revealed more information on the structure of the annealed material. They showed that each single object had well-defined edges, with angles in-between, as well as a characteristic line along the object, probably due to stress. Multiple superposed objects are shown in figure 8 . Although these objects seem aligned in a geometrical fashion, this cannot be generalized, as other stochastic attachment modes were also observed. The well-defined edges of the objects can be an indicator of crystallinity. The crystallinity was confirmed by electron diffraction where clear patterns have been observed. The diffraction pattern in figure $8 \mathrm{c}$ indicates that the objects have a crystalline structure with a hexagonal symmetry. The atomic inter-planar distance, measured using the electron diffraction pattern, is approximately $0.42 \mathrm{~nm}$.

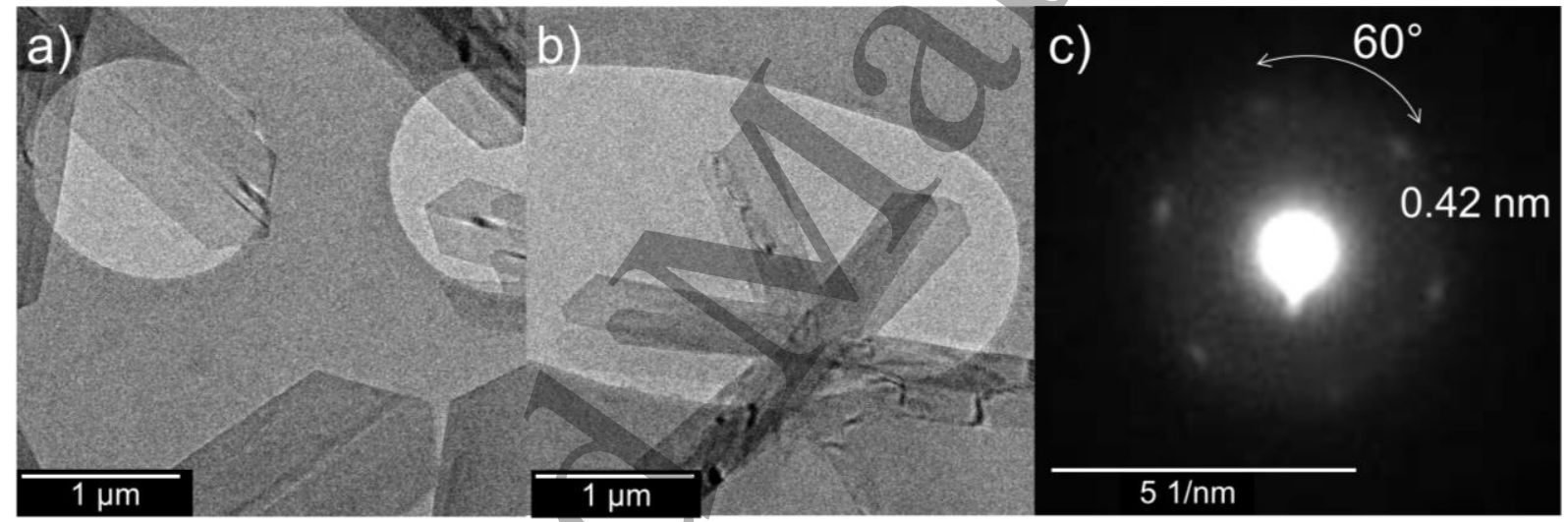

Figure 8. a) and b) TEM images and c) electron diffraction pattern of the annealed material at $500{ }^{\circ} \mathrm{C}$ for two hours. Bright areas in a) and b) are the holes present in the holey carbon film of TEM grid.

As a summary, the as-synthesized material consists of hydrogenated amorphous carbon (see the FTIR measurements) combined with graphite-like carbon in a crystalline phase. Figure 9 shows high-resolution TEM images (figure 9a), magnified at the atomic level (figure 9b and c). In these images, we can clearly see ordered and disordered local regions. Interestingly, the value of the atomic inter-planar distance obtained by our measurements, $0.41 \mathrm{~nm}$ (figure $9 \mathrm{~b}$ ), 
is in good agreement with that previously determined $(0.42 \mathrm{~nm})$ from the electron diffraction patterns of the annealed sample (figure 8c).

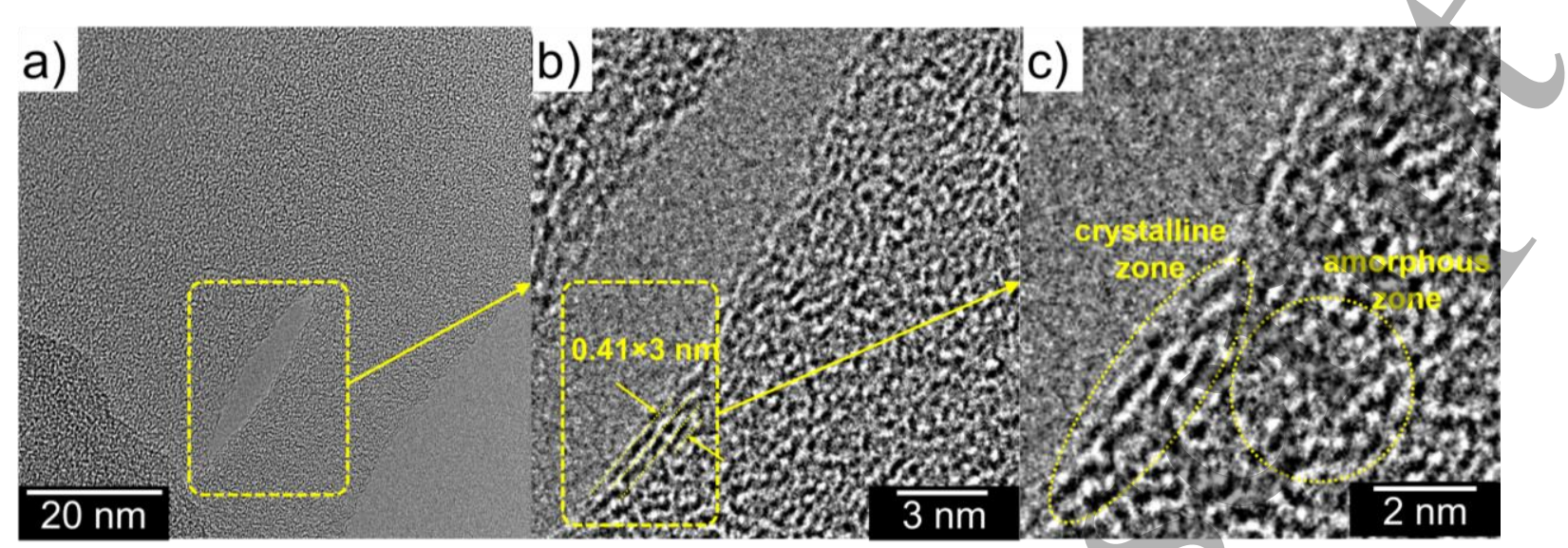

Figure 9. High resolution TEM images showing the region that contains both crystalline and amorphous carbon.

However, further investigations are necessary to fully understand the physicochemical mechanisms involved in the synthesis of our carbon-based material, using the proposed layered in-liquid discharge. For example, since the discharges occurred along the $n$-heptane-water interface (figure 1), the effects of reactive species originated from water, such as hydroxyl radicals and hydrogen peroxide, should be investigated. The physics underlying the discharge in $n$-heptane was previously studied in spark discharge mode [27] and in microwave discharge $[49,50]$, but not in streamer mode. Although these two discharge modes appear similar, they have relatively different plasma properties. In spark mode, the plasma-electrode interaction is key, as it induces significant material evaporation from the electrode that changes the plasma's properties and, as a result, the dissociation mechanisms of $n$-heptane. In this case, the dynamics of the radical is highly affected, and the majority of the synthesized material is nanocompositelike [27, 31]. Lebedev et al. [50] previously studied the decomposition of $n$-heptane by microwave plasma, and their main conclusion was that the heptane was dissociated thermally, i.e., pyrolysis, and that the chemistry induced by electrons played a role only at the plasma ignition stage (millisecond time scale). 
Microwave discharge in $n$-heptane (and generally in hydrocarbons) is generally induced by a metallic electrode that facilitates the ignition process. This discharge mode, however, induces an erosion of the electrode and pollutes the carbon material. In streamer mode, there is no comprehensive theory of the plasma physics and chemistry in $n$-heptane that is induced by a nanosecond discharge. Further diagnostics, for example a gas or liquid by-products analysis, and time and space resolved optical emission spectroscopy, would be valuable tools to help us understand the kinetics, and thus the material synthesis process.

\section{Conclusion}

We introduce an innovative technique for synthesizing nanomaterials in liquids, using a nanosecond electrical discharge. This new technique is based on the fact that mixing polar and non-polar liquids with various densities leads to the formation of an interface, and that approaching the interface position to the tip of an anode highly increases the electric field intensity at the electrode tip and at the interface. In our study, when the electrode tip is positioned at the interface, the discharge being created along the $n$-heptane-water interface produces the dissociation of both liquids, and the synthesis of carbon-based nanomaterials.

A characterization of the produced material, using FTIR, SEM, TEM, and Raman spectroscopy, shows that it consists of a combination of hydrogenated amorphous carbon with a graphene-like crystalline structure. In order to separately characterize these two phases, the material is annealed to release unstable groups. The crystalline structure is confirmed by the shape of the annealed material and by electron diffraction patterns. The inter-planar distance obtained from diffraction patterns is in agreement with that obtained from high-resolution TEM images. Although the physical and chemical properties of the synthesized nanomaterial have not been determined yet, our new technique for synthesizing nanomaterials appears promising and deserves further investigations. 


\section{Acknowledgement}

The research reported in this publication was supported by funding from King Abdullah 


\section{Referenes}

[1] Novoselov K S, Jiang D, Schedin F, Booth T J, Khotkevich V V, Morozov S V and Geim A K 2005 Proceedings of the National Academy of Sciences of the United States of America, 102(30), p.10451-10453.

[2] Geim A K 2009 Science, 324(5934), p.1530-1534.

[3] Robertson J 2002. Materials Science and Engineering: R: Reports, 37(4-6), p.129-281.

[4] Robertson J 1986 Advances in Physics, 35(4), p.317-374.

[5] Saito R, Dresselhaus G and Dresselhaus M S 1998 Physical properties of carbon nanotubes, World Scientific.

[6] Naess S N, Elgsaeter A, Helgesen G and Knudsen K D 2009 Science and technology of advanced materials, 10(6), p.065002.

[7] Sloan J, Dunin-Borkowski R E, Hutchison J L, Coleman K S, Williams V C, Claridge J B, York A P, Xu C, Bailey S R, Brown G and Friedrichs S 2000 Chemical Physics Letters, 316(3-4), p.191-198.

[8] Stankovich S, Dikin D A, Dommett G H, Kohlhaas K M, Zimney E J, Stach E A, Piner R D, Nguyen S T and Ruoff R S 2006 Nature, 442(7100), p.282.

[9] Roy D, Chhowalla M, Wang H, Sano N, Alexandrou I, Clyne T W and Amaratunga G A J, 2003 Chemical Physics Letters, 373(1-2), p.52-56.

[10] Yakobson B I and Avouris P 2001 Mechanical properties of carbon nanotubes. In Carbon nanotubes (p. 287-327). Springer, Berlin, Heidelberg.

[11] Charlier J C and Rignanese G M 2001 Physical Review Letters, 86(26), p.5970.

[12] Manis-Levy H, Livneh T, Zukerman I, Mintz M H and Raveh A 2014 Plasma Science and Technology, 16(10), p.954.

[13] Westberg H, Boman M, Norekrans A S and Carlsson J O 1992 Thin Solid Films, 215(2), p.126-133.

[14] Prenzel D, Kirschbaum R W, Chalifoux WA, McDonald R, Ferguson M J, Drewello T and Tykwinski R R 2017 Organic Chemistry Frontiers, 4(5), p.668-674.

[15] Szafert S and Gladysz J A 2003 Chemical reviews, 103(11), p.4175-4206.

[16] De Greef N, Zhang L, Magrez A, Forró L, Locquet J P, Verpoest I and Seo J W 2015 Diamond and Related Materials, 51, p.39-48.

[17] Wu H, Zhou Z, Chen L, Li W, Han Q, Li C, Xu Z and Qian X 2018 Materials Letters https://doi.org/10.1016/i.matlet.2018.01.075

[18] Plata D L, Hart A J, Reddy C M and Gschwend P M 2009 Environmental science \& technology, 43(21), pp.8367-8373.

[19] Medina C, Santos-Martinez M J, Radomski A, Corrigan O I and Radomski M W 2007 British journal of pharmacology, 150(5), p.552-558.

[20] Abdullaeva Z, Omurzak E, Iwamoto C, Ganapathy H S, Sulaimankulova S, Liliang C and Mashimo T 2012 Carbon, 50(5), p.1776-1785.

[21] Sano N and Ukita S I 2006 Materials chemistry and physics, 99(2-3), p.447-450.

[22] Kang J, Li O L and Saito N 2013 Carbon, 60, p.292-298. 
[23] Lebedev Y A, Konstantinov V S, Yablokov M Y, Shchegolikhin A N and Surin N M 2014 High Energy Chemistry, 48(6), p.385-388.

[24] Hamdan A, Marinov I, Rousseau A and Belmonte T 2013 Journal of Physics D: Applied Physics, 47(5), p.055203.

[25] Kolb J F, Joshi R P, Xiao S and Schoenbach K H 2008 Journal of Physics D: Applied Physics, 41(23), p.234007.

[26] Bruggeman P and Leys C 2009 Journal of Physics D: Applied Physics, 42(5), p.053001.

[27] Hamdan A, Noel, C, Ghanbaja J, Migot-Choux S and Belmonte T 2013 Materials Chemistry and Physics, 142(1), p.199-206.

[28] Belmonte T, Hamdan A, Kosior F, Noël C and Henrion G 2014 Journal of Physics D: Applied Physics, 47(22), p.224016.

[29] Hamdan A, Abdul Halim R, Anjum D and Cha M S 2017 Plasma Processes and Polymers, 14(12).

[30] Tabrizi N S, Xu Q, Van Der Pers N M, Lafont U and Schmidt-Ott A 2009 Journal of nanoparticle Research, 11(5), p.1209.

[31] Hamdan A, Noël C, Ghanbaja J and Belmonte T 2014 Plasma Chemistry and Plasma Processing, 34(5), p.1101-1114.

[32] Lebedev Y A, Epstein I L, Shakhatov V A, Yusupova E V and Konstantinov V S 2014 High Temperature, 52(3), p.319-327.

[33] Gangwar R K, Hamdan A and Stafford L 2017 Journal of Applied Physics, 122(24), p.243301.

[34] Hamdan A and Cha M S 2016 AIP Advances, 6(10), p.105112.

[35] Jiang T and Xu K 1995 Carbon, 33(12), p.1663-1671.

[36] Hong J, Goullet A and Turban G 2000 Thin Solid Films, 364(1-2), p.144-149.

[37] Li Q, Weng S, Wu J and/Zhou N 1998 The Journal of Physical Chemistry B, 102(17), p.3168-3174.

[38] Chu P K and Li L 2006 Materials Chemistry and Physics, 96(2-3), p.253-277.

[39] Wen J, Zeng Z, Yang L, Zeng Q, Lou H, Sheng H, Miller D J, Yang W and Mao H K 2017 Microscopy and Microanalysis, 23(S1), p.2268-2269.

[40] Ferreira E M, Moutinho M V, Stavale F, Lucchese M M, Capaz R B, Achete C A and Jorio A 2010 Physical Review B, 82(12), p.125429.

[41] Chu P K and Li L 2006 Materials Chemistry and Physics, 96(2-3), p.253-277.

[42] Burkey D D and Gleason K K 2003 Journal of applied physics, 93(9), p.5143-5150.

[43] Grill A and Neumayer D A 2003 Journal of applied physics, 94(10), p.6697-6707.

[44] Maex K, Baklanov M R, Shamiryan D, Lacopi F, Brongersma S H and Yanovitskaya Z S 2003 Journal of Applied Physics, 93(11), p.8793-8841.

[45] Perim E, Machado L D and Galvao D S 2014 Frontiers in Materials, 1, p.31.

[46] Xie X, Ju L, Feng X, Sun Y, Zhou R, Liu K, Fan S, Li Q and Jiang K 2009 Nano letters, 9(7), p.2565-2570.

[47] Rurali R, Coluci V R and Galvao D S 2006 Physical Review B, 74(8), p.085414. 
[48] Coluci V R, Braga S F, Baughman R H and Galvao D S 2007 Physical Review B, 75(12), p.125404.

[49] Lebedev Y A, Konstantinov V S, Yablokov M Y, Shchegolikhin A N and Surin N M 2014 High Energy Chemistry, 48(6), p.385-388.

[50] Lebedev Y A, Tatarinov A V and Epstein I L 2017 Plasma Physics Reports, 43(4), p.510513. 


\section{CAPTIONS}

Figure 1. a) Schematic of the experimental setup (not drawn to scale) showing the anode, the cathode, n-heptane, water, and the interface. b) ICCD image (integrated over $1 \mu \mathrm{s}$ ) of the discharge at the interface $\mathrm{n}$-heptane-water ( $15 \mathrm{kV}$ of applied voltage and $2 \mathrm{~mm}$ of gap distance). c) $2 \mathrm{D}$ electric field simulation using Comsol Multiphysics for conditions similar to b). d) Electric field profile along a line (the red line in the inset) crossing the interface close to the anode.

Figure 2. FTIR spectra (absorbance) of untreated liquid n-heptane, liquid-treated n-heptane, and synthesized solid particles.

Figure 3. Fitting of the FTIR spectra (absorbance) of a) treated liquid n-heptane and b) synthesized solid particles.

Figure 4. SEM images of the as-synthesized material deposited onto an aluminum substrate. a) Image showing multiple sheets; b) image showing one single sheet decorated by nanoparticles.

Figure 5. TEM images of the as-synthesized material at a) low, b) intermediate, and c) high resolution. d) Electron diffraction pattern of the as-synthesized material. e) Electron energy loss spectrum of the as-synthesized material.

Figure 6. Raman spectrum of the as-synthesized material showing D and G peaks at 1389 and $1596 \mathrm{~cm}^{-1}$.

Figure 7. a) SEM images of the annealed material at $500{ }^{\circ} \mathrm{C}$ for two hours, with. b), c), and d) showing various regions of a) at higher magnification.

Figure 8. a) and b) TEM images and c) electron diffraction pattern of the annealed material at $500{ }^{\circ} \mathrm{C}$ for two hours. Bright areas in a) and b) are the holes present in the holey carbon film of TEM grid.

Figure 9. High resolution TEM images showing the region that contains both crystalline and amorphous carbon. 